\title{
EL DOCUMENTAL INTERACTIVO EN LA CULTURA DE CONVERGENCIA Y LAS NARRATIVAS TRANSMEDIA
}

\author{
Maximiliano de la Puente; Lorena Díaz Quiroga *
}

\begin{abstract}
Artigo revisto após publicação, com o objetivo de atender a procedimentos de citação. Revisão ocorrida a 02 de dezembro de 2017.

Artículo revisado después de la publicación con el objetivo de atender a los procedimientos de citación. Revisión ocurrida en 02 de deciembre de 2017.

Revised article after publication with the purpose of attending citation procedures. Revision occurred on December 2nd 2017.

Article révisé après publication afin de se conformer aux procédures de citation. La révision a eu lieu le 02 de novembre 2017.
\end{abstract}

Resumo: Neste trabalho abordamos um dos principais temas da cultura da convergência e narrativas transmídia: o documentário multimídia interativo. Tentaremos definir um objeto complexo, apontar suas principais características e diferenciá-lo do documentário linear tradicional. Teremos em conta as reflexões de vários dos principais especialistas no campo, especialmente as considerações de Arnau Gifreu Castells. Como ele argumenta, encontramos um objeto inserido num ecossistema em constante mutação, caracterizado por um ambiente digital em rápida evolução. A poluição e confusão terminológica é grande e não existe uma única maneira de nos referirmos a esses documentários. Vários termos convivem como "documentário novos meios de comunicação", "biblioteca digital", "WebDocs" ou "webdocumentales", "filmes interativos", explorações interativas", "ensaios digitais", etc. Este artigo é dedicado à descrição e análise das suas características centrais.

Palavras-chave: documentário, interatividade, convergência, transmedia.

Resumen: En este trabajo abordaremos uno de los tópicos principales de la cultura de la convergencia y las narrativas transmedia: el documental multimedia interactivo. Intentaremos definir un objeto complejo, señalaremos sus principales características y lo diferenciaremos del documental lineal tradicional. Tomaremos para ello las reflexiones de varios de los más destacados especialistas en el tema, centrándonos especialmente en las consideraciones de Arnau Gifreu Castells. Como éste sostiene, nos encontramos con un

\footnotetext{
* Maximiliano de la Puente: Doctorando. Universidade de Buenos Aires, Facultad de Ciencias Sociales, Programa de Doctorado en Ciencias Sociales. 2230, Buenos Aires, Argentina. E-mail: maxidelapuente@gmail.com Lorena Díaz Quiroga: Directora de Fotografia, ENERC - Escuela Nacional de Realización y Experimentación Cinematográfica. 1091, Buenos Aires, Argentina.

E-mail: lodikua@gmail.com
}

Submissão do artigo: 31 de maio de 2015. Notificação de aceitação: 20 de agosto de 2015. 
objeto inserto en un ecosistema en transformación constante, caracterizado por un entorno digital en rápida evolución. La contaminación y confusión terminológica es tal, que ni siquiera existe una única manera para referirse a estos documentales. Conviven así expresiones como "documentales de nuevos medios", "documentales digitales", "webdocs" o "webdocumentales", "películas interactivas", "bases de datos narrativas", "exploraciones interactivas", "visitas virtuales", "ensayos digitales", etc. A la descripción y el análisis de sus características centrales, se dedicará este artículo.

Palabras clave: documental, interactividad, convergencia, transmedia.

\begin{abstract}
In this article we approach one of the main topics of the culture of convergence and transmedia narratives: the interactive multimedia documentary. We try to define a complex object, point out their main characteristics and differentiate from the traditional linear documentary. We will take for the reflections of several of the leading specialists in the field, especially focusing on considerations of Arnau Gifreu Castells. As he argues, we find an object insert in a constantly changing ecosystem, characterized by a rapidly evolving digital environment. Pollution and terminological confusion is such that there is not even a single way to refer to these documentaries. Thus, coexists expressions as "new media documentary", "digital library", "webdocs" or "webdocumentales", "interactive movies", "narrative data bases", "interactive explorations", "digital essays", etc. This article describes and analyzes its main features.
\end{abstract}

Keywords: documentary, interactivity, convergence, transmedia.

Résumé: Dans cet article, nous abordons l'un des principaux thèmes de la culture de la convergence et de récits transmédia: le documentaire multimédia interactif. Nous Essayons de définir un objet complexe, souligner leurs principales caractéristiques et de le différencier par rapport au documentaire linéaire traditionnelle. Nous allons considérer les réflexions de plusieurs des plus grands spécialistes dans le domaine, en particulier ceux de Arnau Gifreu Castells. Comme il fait valoir, nous trouvons un objet inséré dans un écosystème en constante évolution, caractérisé par un environnement numérique en constante évolution. La pollution et confusion terminologique est telle qu'il n'y a pas un terme unique pour se référer à ces documentaires. Divers termes coexistent: "documentaire des nouveaux médias", "bibliothèque numérique", "webdocs" ou "webdocumentales», «films interactifs», «bases de données narrative», «explorations interactives", "tour", "essais numériques", etc. Cet article est consacré à la description et l'analyse de ses principales caractéristiques.

Mots-clés: documentaire, interactivité, convergence, transmédia.

\title{
Introducción
}

En este trabajo abordaremos uno de los tópicos principales de la cultura de la convergencia y las narrativas transmedia: el documental multimedia interactivo. Intentaremos definir un objeto sumamente complejo, aún en construcción, y señalaremos sus principales características. Tomaremos para ello las reflexiones de varios de los más destacados especialistas en el tema, centrándonos especialmente en las 
consideraciones de Arnau Gifreu Castells. Como éste sostiene, nos encontramos con un objeto inserto en un ecosistema en transformación constante, caracterizado por un entorno digital en rápida evolución. La contaminación y confusión terminológica es tal, que ni siquiera existe una única manera para referirse a estos documentales. Conviven así expresiones como "documentales de nuevos medios", "documentales digitales", "webdocs" o "webdocumentales", "películas interactivas", "bases de datos narrativas", “exploraciones interactivas", "visitas virtuales", “ensayos digitales", etc.

El desarrollo de un lenguaje hipertextual promueve cambios de magnitud, al alterar los mecanismos tradicionales de interpretación de un mensaje y generar un incremento en las posibilidades de hibridación genérica. Por su propia índole, el hipertexto profundiza en la densidad interpretativa de los mensajes. "La hipertextualidad proporciona un criterio exclusivo de ordenamiento, de acuerdo con las demandas de un marco de categorización específico para los géneros de no ficción interactiva" (Gifreu Castells: 2013). En el marco del hipertexto, el documentalista ya no posee el dominio total sobre el sentido final de su producto. En el documental interactivo puede sustituirse una estructura dramática clásica que se apoya fuertemente en un inicio, un cuerpo central y un final, por nudos temáticos que se utilizan para desarrollar el tema y contextualizar, narrar los antecedentes del caso, incluir información complementaria y documentar el hecho en cuestión. Estos bloques pueden combinarse con núcleos argumentativos o de opinión, a través de enlaces a blogs, redes sociales, etc. El documental interactivo asume la forma de un "metagénero" que contiene formatos, discursos y múltiples experiencias de diversos usuarios.

Desde sus inicios, el género documental se ha constituido en una de las herramientas más eficaces para contar historias de no ficción sobre "la realidad". A lo largo del siglo XX y en lo que va del XXI, el género ha pasado de una búsqueda de representación más o menos "transparente" de lo 
real a desarrollar experiencias que evidencian explícitamente la subjetividad del realizador, en donde la relación con el referente externo a las películas se desdibuja por completo. El documentalista irrumpe, marca, deja huellas en el espacio fílmico/real, realiza un acto performativo que incide sobre este último.

Por su parte, la posibilidad de que los usuarios puedan elegir y adquieran control sobre el propio documental, (un espacio reservado anteriormente en exclusividad para el realizador), se profundiza con el desarrollo de los medios interactivos, los mundos virtuales y los videojuegos. El espectador interactivo puede asumir en algunos casos el rol de cocreación de la propia experiencia documental, aunque por lo general ocupando un rol subsidiario. Por ejemplo, en lugar de editar una película de manera lineal, un documentalista puede crear una base de datos de clips de vídeo y entrevistas, a través de la cual un interactor puede navegar con el uso de una interfaz gráfica de usuario, situación que permite que el usuario profundice en asuntos de su propio interés, generando así una experiencia documental muy personal. Los documentales interactivos se producen con el fin de visualizarse y experimentarse en distintos soportes, ya que más allá de aquellos que se producen para ser vistos a través de una computadora o un dispositivo móvil, muchos otros documentales se han creado también para DVD o consolas de videojuegos. En este escenario, el espectador y/o jugador es también un usuario y un lector.

\section{La representación de la realidad}

Josep Maria Català, en su clase magistral: "Reflujos de lo visible. La Expansión post-fotográfica del documental”, señala que ante la aparición de nuevas formas de expresión visual, como el "Comic book documental" o el "Webdocumental", que se desvinculan del supuesto realismo que impone la fotografía, pero que al mismo tiempo reclaman su pertenencia dentro del 
ámbito del documental, se impone una revisión de las relaciones existentes entre el fenómeno fotográfico y el tratamiento documental. Las nuevas posibilidades que ofrece el genero, tales como el "Webdocumental", el "Comic book documental" o los "Docugames" y las instalaciones interactivas, ocasionan una fuerte expansión del imaginario del documental, debido al surgimiento de nuevos lenguajes y retóricas, que confluyen en el concepto de "documental expandido". Estas nuevas prácticas del documental ponen al servicio del realizador diversificadas herramientas de utilización.

Desde su mismo nacimiento, el documental fue concebido como un tipo de cine que se planteaba "captar objetivamente la realidad". Con la irrupción del giro subjetivo y ensayístico en el género, desde los años noventa del siglo pasado en adelante, junto con la revolución en el espacio de representación que tuvo lugar una década más tarde, el ámbito fotográfico comienza a desvanecerse o al menos, a ponerse seriamente en cuestión. Así, si al giro subjetivo se le agrega

un documental que se acerca al dibujo - un documental dibujado -, el problema es preguntarnos si esto es un documental, si sigue siendo un documental una pieza que no tiene el registro fotográfico como marca esencial, porque el documental basaba su objetividad y capacidad de captar la realidad en que existía un artefacto que se planteaba captar la realidad mecánicamente sin vestigios de subjetividad. (Gifreu Castells: 2013).

Se modifica entonces sustancialmente, hasta el punto de anularse, el vínculo entre la fotografía y la representación en el documental interactivo, puesto que, por ejemplo, la realidad aumentada puede ser utilizada como medio para incrementar significativamente la potencia expresiva, emocional y epistemológica de la fotografía, en la medida en que aquella implica poder superponer datos a la realidad que vemos, con lo cual estamos alterando por completo el concepto de esta última. 
Català sostiene que el cine documental pertenece a lo que denomina como " la era de la verdad", mientras que a esta supuesta "era de la postverdad" en que vivimos, le correspondería el término de "cine de lo real". Paradójicamente o no tanto, en expresiones documentales contemporáneas, como el comic documental o la novela gráfica documental, desaparece el vínculo fotográfico con la realidad, por lo que el carácter de ficcionalización parece aumentar significativamente, de la misma forma en que una película con imagen fotográfica resulta ser muy verosímil por más alejada de la realidad que se encuentre. $\mathrm{Y}$ esto es así porque la forma documental es mucho más amplia que la forma fotográfica. Sin embargo, en el género documental, aún en sus formas contemporáneas, toda propuesta estética, cualquier recorrido formal que se elija, se realiza siempre sobre una determinada concepción de lo real, solo que este compromiso con lo real ha venido adquiriendo maneras novedosas ya desde mediados del siglo XX en adelante. Con la irrupción irreversible de las imágenes digitales, ingresamos en el ámbito de la imaginación. Surge por ejemplo, en el documental dibujado, la posibilidad de un nuevo registro del documental, el del recuerdo como apertura de significaciones, en lugar de como resultado. Pero por más procedimientos ficcionales que ponga en juego el documental interactivo, existe siempre un compromiso testimonial que funciona como anclaje y que lo aleja del género ficcional.

Català toma el comienzo del documental Las playas de Agnes (2008), de la directora francesa Agnès Varda, cuando vemos a la autora en una playa, mientras dispone diferentes espejos y crea composiciones a partir de reciclar diferentes imágenes reflejadas y de reflexionar en torno a los nuevos significados y relaciones que se establecen de su conjunción. De una manera estéticamente similar, Alejandra Almirón utiliza la cámara subjetiva, así como las fotografías personales y el material de archivo en Equipo verde (2003), para armar una imagen caleidoscópica, múltiple y no exenta de contradicciones y zonas oscuras, no sólo de su adolescencia en 
una escuela pública sino también de la dictadura argentina. En esta necesidad de fragmentación contemporánea, en este esfuerzo por romper la unidad de lo que entendemos por realidad, pero al mismo tiempo de recomponer y dar otros múltiples sentidos a las diferentes partes, se desarrollan las formas documentales contemporáneas. Con el advenimiento de las nuevas tecnologías de la información y la comunicación, los responsables de producir los documentales contemporáneos están participando en el proceso de profundizar los cambios que ya vienen teniendo lugar en el campo del documental desde hace décadas. Estos creadores imaginan lo que el documental podría llegar a ser, con atributos relacionados como "no lineal", "multimedia", "interactivo", "híbrido", "plataformas", "convergente", "virtual”, u otros términos o categorías más aún por inventar.

\section{Características principales}

Como ya hemos mencionado, uno de los aspectos centrales de los documentales interactivos, es que en algunos casos pueden otorgarle un gran poder al usuario y el realizador pierde al menos en parte el control de su obra. El resultado final del producto documental puede adoptar una forma muy diferente a la que, en un estadio inicial, el director había plasmado en un guión. En esta situación de autoría compartida el realizador asume un papel más bien asistencial con respecto al usuario/interactor, ya que este último debe aprender unas pautas y mecanismos sin los cuales no podrá avanzar a través de la narración. Cuanto más variados y diversificados sean los desarrollos de los sistemas interactivos, y por ende cuantas más opciones tenga el interactor, mucho mejor.

Los documentales interactivos se encuentran enmarcados dentro de un género interactivo más general, que se podría definir como el de las 
aplicaciones interactivas multimedia de carácter divulgativo y documental. El documental interactivo se vincula con los géneros de no ficción interactiva, y se articula mediante una voluntad de transmisión de conocimiento a partir de la educación informal. Nos referimos a proyectos que muestran una clara intención de divulgación, y en los que existen una forma determinada de interactuar con el sistema, es decir que el usuario debe tomar decisiones para avanzar en el sistema hipertextual. Por educación informal, entendemos un conjunto de procesos permanentes a través de los cuales las personas adquieren y acumulan conocimientos, habilidades, actitudes y modos de discernimiento, a partir de las experiencias diarias y su relación con el entorno.

Cabe señalar que el webdoc o Webdocumental es sólo un subgénero dentro del género mucho más amplio del documental interactivo. En este sentido, hay que diferenciar entre las aplicaciones en línea y aquellas que se encuentran fuera de línea o "offline". Mientras que estas últimas se localizan en soportes físicos, las primeras utilizan un soporte virtual, como la red de redes. Los géneros fuera de línea se asocian generalmente a plataformas pertenecientes a la Web 1.0, a través de soportes cerrados a la aportación del usuario, mientras que las aplicaciones en línea se vinculan a una red con atributos colaborativos y generativos por parte del interactor. En tanto sistema abierto y generativo, Gaudenzi (2009), caracteriza al documental interactivo como un mecanismo "autopoiético" un organismo vivo que se relaciona con su entorno a través de los diferentes modos de interacción.

La interacción que proponen estos documentales puede ser de distintos niveles y expresarse en diversas formas, ya sea corporal, ya sea a través del mouse, como mediante otros dispositivos de interacción (guantes, sensores, microcontroladores, etc.), y que incentiven al usuario/interactor a participar y generar contenidos. Según Berenguer (2004), existen tres tipos de interacción: fuerte, mediana y débil. Gifreu Castells (2013) sostiene que, 
en el caso de los documentales interactivos, la aplicación debe utilizar tecnología digital desde el punto de vista de la interacción mediana o fuerte (debe involucrar al usuario hacia un tipo de respuesta física, en el sentido fuerte del término). El usuario puede interactuar a partir de la interfaz (y sus modalidades de navegación) o a partir de los contenidos y/o los otros usuarios (modalidades de interacción). Así, los espectadores de este nuevo formato incorporan las condiciones de usuario, en la medida en que forman parte de un sistema preestablecido y lo utilizan para sus intereses; de interactor, porque interactúan con la interfaz para avanzar en el desarrollo propuesto; de participante, ya que participan activamente en el desarrollo, eligiendo la línea narrativa que les parezca más adecuada, y de contribuidor, porque contribuyen a la generación del sistema y aportan conocimiento a base de contenidos o impresiones subjetivas.

\section{Sobre la interactividad}

Como ya hemos dicho, en las aplicaciones interactivas la progresión del discurso requiere el procesamiento de las acciones del usuario. La presentación lineal y esquemática de la información es reemplazada para ofrecer una interacción directa del usuario articulado a través del propio medio. Al ser un concepto excesivamente amplio, usado en exceso y en parte mistificado, es necesario acotar su definición. Seguimos aquí a Gifreu Castells cuando piensa la interactividad exclusivamente asociada al vínculo que el espectador mantiene con el contenido del documental, en el nivel de la interfaz hombre-máquina. El mismo nivel en que "todo el contenido digital se puede reordenar, reorganizar y abrir a una interpretación subjetiva" (Stuart Dinmore en Gifreu Castells: 2013). Así, el espectador de documentales interactivos puede intervenir como coeditor, al tener la capacidad de reconstruir el orden y la yuxtaposición de los elementos multimedia. Las modalidades que refieren a la producción, el análisis, la 
distribución y la recepción de los productos audiovisuales varían significativamente, debido a la contraparte no lineal interactiva. Si bien tanto las disciplinas artísticas tradicionales como los antiguos medios de comunicación de masas son interactivos en un sentido amplio, aquí se piensa la interactividad al nivel en que se realiza una selección textual y se excluyen otras, lo que permite un pasaje único para cada usuario a través del sistema hipertextual.

Siguiendo a Xavier Berenguer (2004), se puede pensar en una interacción fuerte, mediana y débil, en función del grado de apertura y de posibilidades de manipulación que ofrezcan. Como él mismo sostiene:

A un nivel bajo, el interactor se limita a escoger entre un menú de opciones. Un nivel algo superior consiste en tener que localizar estas opciones o, más aún, al tener que responder a determinadas pruebas o superar ciertos obstáculos para poder avanzar en la exploración del interactivo. En los niveles altos, el interactor se ve sometido a demandas aún mayores: participar como protagonista del entorno interactivo, contribuir e incluso modificarlo. Se puede hablar, pues, de una interacción débil - así es actualmente la de la mayoría de webs - y de una interacción fuerte, la expresión máxima (participativa, contributiva y comunitaria) se conoce como realidad virtual. Pero no se trata, necesariamente, de maximizar la intensidad de la interacción. En cada género interactivo, y a cada programa en particular, corresponde una interacción más o menos fuerte. La difusión de información, por ejemplo, precisa de un grado débil (sería absurdo, por ejemplo, poner obstáculos para encontrar el significado de una palabra en una enciclopedia). Por su parte, el documental y la no ficción se prestan a una interacción media (idónea para regular el ritmo de asimilación), mientras que la ficción y, en general, la creación libre, permiten la interacción en el sentido más fuerte. (Berenguer: 2004).

Para Berenguer, el diseño de un sistema interactivo consiste en encontrar el grado óptimo con el que la computadora "habla", "piensa" y “escucha", lo cual requiere, para la producción de un sistema de tales características, el desarrollo de habilidades audiovisuales y a la vez informáticas. 


\section{Interacciones e interactores}

Desde esta perspectiva, existen dos tipos de motivaciones completamente distintas en el usuario, al encontrarse frente a un producto interactivo: extrínsecas e intrínsecas. Las motivaciones extrínsecas son ajenas a aquel: una persona que consulta un concepto en Wikipedia o la programación de una cadena de televisión en su sitio web, o videos en YouTube, necesita sólo que se le facilite un acceso rápido y sin obstáculos. Por el contrario, un usuario que decide instalar un CD-ROM, o ingresar a la extensión interactiva de una exposición en la web de un museo o de una serie de televisión, puede tener un interés específico, intrínseco, en el producto interactivo que consulta. Puede llegar a tomar parte en propuestas imprevistas que provoquen y estimulen este interés inicial y que incluso lo vayan llevando a modificar, adaptar o sustituir sus objetivos iniciales.

Marie Laure Ryan (2001), define cuatro formas estratégicas de la interactividad en base a dos pares binarios: interna/externa y de exploración/ontológica. En el modo interno, el usuario se reconoce como un miembro del mundo de ficción, ya sea como avatar o en una perspectiva en primera persona, mientras que en la forma externa se sitúa fuera del mundo virtual. En el modo de exploración, el usuario es capaz de navegar por la base de datos para decidir el camino a seguir, pero no tiene impacto real en el mundo virtual. La forma ontológica sucede cuando los usuarios tienen el poder de cambiar el mundo. (Ryan: 2005). El exterior e interior puede ser visto como una opción decidida por el autor para aumentar el nivel de inmersión del usuario. La inmersión es la sensación de "estar rodeado de una realidad completamente diferente" (Murray: 1997). En un documentaljuego como America 's Army (2002), la sensación de inmersión es muy alta,

y esto hace que el jugador suspenda su incredulidad, y acepte la lógica 
interna de la experiencia, que es, en este caso, disparar a la gente. (Bonino: 2011).

\section{Tipos de narrativas interactivas}

Florent Maurin (2011), por su parte, señala que la interactividad puede ser utilizada como herramienta expresiva con distintos fines y objetivos. Puede transmitir emociones, como el caso del proyecto Bla bla bla 69 (http://blabla.onf.ca/), conectar significado y significante, como en el caso del proyecto La vie en sac70 (http://www.lavieasac.com/), fomentar la exploración, como en el caso del proyecto Sacremontagne71 (http://sacreemontagne.onf.ca/), y desencadenar y provocar estimulación al usuario a partir de la creación de pruebas, como en el caso de Darfur Game72 (http://www.radiodabanga.org/darfurgame/english/game.html).

Establece una tipología de narrativas interactivas que caracterizan a los documentales de esta índole. La narrativa lineal, como ya sabemos, constituye la forma clásica de narrar basada en una sola historia posible. Los acontecimientos se suceden en un orden definido por el narrador. Se trata de un tipo de narrativa sencilla de generar y de usar, de fácil transmisión de emociones al usuario en la que no hay saturación de información. Debido a la poca interacción que produce, cada usuario obtiene la misma experiencia. Ejemplos de este tipo de narración, son los siguientes documentales: Le corps incarcéré (http://www.lemonde.fr/societe/visuel/2009/06/22/le-corpsincarcere_1209087_3224.html), Where is Gary (http://whereisgary.net/) y Bucarest Below Ground (http://www.bombayfc.com/bucharest_uk/).

La narrativa concéntrica es aquella en la que los usuarios tienen acceso a un esquema o mapa general de los diferentes contenidos y secciones, visitándolas en el orden que deseen. Ofrece la posibilidad de ordenar fragmentos heterogéneos que parecen adquirir sentido a través de su unión. Las desventajas que posee es que el punto de vista del autor puede 
debilitarse o desaparecer, y se detecta demasiada saturación de información simultánea: sólo los usuarios más motivados accederán a todas las secciones. Ejemplos son: Vies de jeunes (http://www.lemonde.fr/ societe/visuel/2011/06/10/vie-de-jeunes-a-l-age-ou-tout-oscille_1534639_ 3224.html), The iron curtain diaries (http://www.theironcurtaindiaries.org/) y Behind the veil (http://www.theglobeandmail.com/news/world/behind-theveil/) .

La narrativa "Espina de pescado" o "banda elástica" presenta una historia lineal central y circunvalaciones a subhistorias que vuelven al eje central. Se trata de una combinación equilibrada entre narración e interacción. La gran desventaja que tiene es que justamente parece muy semejante a una historia lineal, lo cual puede provocar que el usuario se aburra o que no tenga interés para consultar las subhistorias. Cada subhistoria puede, a su vez, alejar al espectador del flujo original, haciendo que pierda interés por la historia inicial. Maurin destaca Welcome to Pine Point (http://pinepoint.nfb.ca/\#/pinepoint) y Prison Valley (http://prison valley.arte.tv/?lang=en).

La narrativa ramificada implica que en momentos definidos, el usuario deba tomar decisiones que lo llevarán hacia un nodo determinado de la historia. Constituye una estructura potencialmente muy interactiva con poca saturación de información, debido a que los usuarios siempre se encuentran involucrados en la historia a partir de sus decisiones y siempre quieren saber más. Entre los ejemplos de este tipo de narrativa, se destacan: Journey to the end of coal (http://www.honkytonk.fr/index. php/webdoc/) y en general todos los proyectos creados con el software Klynt.

En la narrativa paralela conviven diferentes ejes, pero nunca uno termina en otro, sino que la historia contempla diferentes nudos y desenlaces, por lo que se basa en una narrativa ramificada. Ofrece una buena interacción, aunque los caminos y los nodos son previamente definidos. 
Destacamos Tanatorama (http://www.thanatorama.com/) y Premiers combats (http://www.premierscombats.com/).

La narrativa enroscada consiste en explicar una historia a partir de diferentes puntos de vista. Debido a su estructura, se salta de nodo a nodo pero no hay que pasar por el eje principal. Debido a que conviven muchas historias dentro de la misma historia o tema, idealmente los usuarios pueden moverse a través de muchas partes de la narrativa simultáneamente. Esto genera una gran saturación de información y un tipo de diseño interactivo complejo, que vuelve necesario seleccionar la información a visualizar, haciendo que el usuario pase por otras historias antes de llegar a lo más importante. Ejemplos de esta narrativa son: Gaza Sderot (http://gazasderot.arte.tv/) e Inside the haiti earthquake (http://www.insidedisaster. com/experience/).

Finalmente, la narrativa dinámica orientada a objetos, está definida por pequeñas historias que incluyen puntos de entrada y salida. Su estructura equivale a minicapítulos de un libro o escenas de una obra, pero menos estrictos en su orden de lectura, ya que no es necesario leerlos todos ni seguir un orden determinado. La concatenación de todas estas historias funciona como una narrativa paralela. Los usuarios no se sienten nunca perdidos, la historia completa sólo es percibida al final. Se trata de una mezcla de roles entre autor y usuario, este último puede llegar al final pero no entenderlo, ya que se ha perdido algún módulo concreto previo. Los ejemplos significativos son Soul Patron (http://www.soul-patron.com/) y Façáde (http://www.interactivestory.net/), aunque este último no sea considerado por Maurin como un documental interactivo propiamente.

\section{Análisis de caso: Prison Valley}

En este apartado retomamos y sintetizamos las reflexiones que desarrolla Roberto Arnau Roselló (2014) sobre este documental interactivo. 
Tal como este último sostiene, Prison Valley nace de la conjunción entre un periodista, David Dufresne, y un fotógrafo, Michel Brault, lo que no hace más que enfatizar el carácter colaborativo de este tipo de realizaciones. El documental aborda la situación de la industria carcelaria en el condado de Fremont, perteneciente al estado de Colorado en Estados Unidos. Las consideraciones de Arnau Roselló sobre la masiva difusión que alcanzó este documental interactivo son contundentes, pues señala que:

El día del estreno en la web la notoriedad es instantánea, la plataforma recibe más de 1.000 .000 visitas. Los días posteriores el número se reduce a 400.000, con millones de videos visionados por los internautas. Además, se cuentan unos 100.000 accesos a través de otras plataformas web colaboradoras, como el periódico Libération o la cadena televisiva Arte (que ya ha aportado, a su vez, 500.000 espectadores más por la difusión del documental de 59 minutos en la tv francesa), a lo que finalmente hay que sumar unas 15000 visitas al mes sostenidas durante el año 2011, hasta principios de 2012. El éxito sin precedentes de una obra de este tipo y su innegable calidad abonan el terreno para que reciba el prestigioso galardón 1er Premio World Press Photo 2011, en la categoría de Interactivo Multimedia, lo que desborda las previsiones iniciales del proyecto y le dota de una proyección internacional al nivel de las producciones cinematográficas de cariz documental más exhibidas de todos los tiempos. (Arnau Roselló: 2014).

Prison Valley es un documental interactivo sumamente interesante puesto que, a la vez que mantiene la narración como el esqueleto estructural central del producto, rompe simultáneamente con la linealidad, a partir de la elaboración de un esquema arborescente o rizomático, en función del tipo de interacción buscada y de los mecanismos empleados para generarla. Con el fin de provocar un interés y una participación decidida del usuario del relato, Prison Valley "cuenta con un amplio abanico de recursos tecnológico-retóricos, una fotografía y un trabajo de diseño de interfase coherente con la articulación discursiva del film (...) Los contrastes generados por el uso del sonido ambiente, el color naranja dominante y los 
claroscuros del interface" (Arnau Roselló: 2014), ubican al espectador en una situación de claustrofobia inmersiva que predomina desde el inicio mismo de la narración. Este documental desarrolla una narración de tipo lineal, en la medida en que su arquitectura hipertextual se apoya "sobre una estructura uniforme que permite retomar la narración documental en cualquier momento en el punto en el que se dejó antes de ejecutar los elementos interactivos. La linealidad de la narración principal contrasta con las líneas de fuga que ofrece el trayecto a partir de enlaces y anclas en las escenas" (Arnau Roselló: 2014). En relación a la puesta en escena, Arnau Roselló afirma que el documental se apoya fuertemente en el género del road-movie, en la medida en que accedemos al recorrido que efectúan los realizadores y sus encuentros con los diversos entrevistados. Prison Valley se conforma como un relato polifónico que desconfía de la supuesta "verdad" que cada uno de los testimonios tiene para transmitir, "pero su validez no se da por sentada sino que supone un punto de partida para ulteriores cuestionamientos de la realidad y la forma en que ésta se (re)presenta" (Arnau Roselló: 2014). El ámbito en el que se desarrolla la acción asume una importancia dramática cardinal.

Los planos en movimiento desde el coche en marcha y el sonido ambiente son una constante, una referencia permanente a una búsqueda incansable y un territorio inhóspito que es un personaje más (quizás el protagonista) y al que la voz over apela repetidamente en busca de respuestas que no acaban de llegar o aún peor, generan más preguntas. (Arnau Roselló: 2014).

A su vez, siguiendo el análisis de este autor, se verifica que la página de inicio (home) no constituye la página central del proyecto, sino que nos ubica frente a una serie de imágenes de perímetros de seguridad vallados, superpuestas con un cuadro de diálogo que nos permite iniciar la interacción con el programa. En esta misma página puede seleccionarse ya el idioma de la voz del narrador y el subtitulado, pudiéndose elegir entre inglés, francés y 
alemán. Es posible también abrir una pestaña de contacto que nos permite mantener correspondencia electrónica con el equipo de producción.

Como sostiene Arnau Roselló, la secuencia introductoria muestra un plano general en movimiento desde dentro de un coche, que nos adentra lentamente en el valle a través de una ruta escarpada y serpenteante en pronunciada pendiente, en medio de en un paisaje semidesértico, a la vez que simultáneamente una voz en off de una mujer "nos revela la procedencia del título del documental" (Arnau Roselló: 2014). La situación de inmersión que se genera en el espectador es intensa y ominosa. Se torna claro sensorialmente que estamos accediendo a un mundo con características siniestras. La cámara subjetiva desde el automóvil se convierte en una suerte de leitmotiv de avance en la progresión del documental, "un motivo recurrente que articula en cierto modo el relato convirtiéndose en otro elemento más que contribuye a la identificación del espectador como protagonista de esta particular investigación" (Arnau Roselló: 2014).

Al llegar al hotel, el documental le demanda al usuario que se registre para poder continuar navegando. “A partir de una lenta panorámica vertical frente al mostrador del motel se nos presenta en pantalla un formulario de registro en una habitación para el que se nos pide un alias y un e-mail de contacto" (Arnau Roselló: 2014). Prison Valley se propone así como un documental netamente inmersivo, en la medida en que el espectador deviene en protagonista de esta narración interactiva. Una interactividad que se encuentra dada también por "la posibilidad de compartir cada pieza en distintas redes sociales como Facebook, Twitter, etc. y en foros específicamente creados para ello" (Arnau Roselló: 2014).

Tal como afirma Arnau Roselló, el ámbito de navegación central del documental interactivo se sitúa de esta forma en la habitación del hotel en el que se hospedan los realizadores durante el rodaje. Desde este lugar, para el que se ha elaborado un espacio sonoro basado en sonidos mecánicos y 
repetitivos, el espectador asume el control del desarrollo narrativo del documental.

En el interior de la habitación, representada por una fotografía de gran formato panorámico desplazable (ya que no podemos ver la habitación completa sin mover nuestro punto de vista) aparecen identificados aquellos elementos interactivos típicos de un motel y de una investigación que despliegan otros contenidos visuales cuya presencia secundaria con respecto al cuerpo central de la aplicación (el documental de 59 minutos) no implica un papel menor en la construcción del sentido. (Arnau Roselló: 2014).

En la habitación del hotel se encuentran dispuestos una gran cantidad

de objetos con los que el usuario puede interactuar. Así, nos topamos con

un teléfono (Recepción) interactivo cuya ejecución despliega automáticamente la fotografía a tamaño casi natural del aparato, un televisor (Infos) interactivo cuya ejecución activa la aparición de un mando a distancia que nos permite cambiar de canal, un ordenador portátil encima de una mesita cuyo click nos lleva directamente a la participación en los foros de la aplicación, un cuaderno de notas (cuaderno) que contiene información hipertextual de los personajes del film, una colección interactiva de indicios y recuerdos (indicios) esparcida por encima de la cama cuyo contenido aumenta a medida que se avanza en el visionado de secuencias, pudiendo llegar a albergar hasta 30 elementos diferentes relativos a personajes o cuestiones centrales de la historia, una ventana sobre el patio (Ventana) que ofrece la vista real desde la ventana de la habitación al patio exterior del motel y, finalmente, una puerta para salir que nos devuelve al punto de la aplicación desde el que hubiésemos accedido a la habitación del hotel. (Arnau Roselló: 2014).

Otro de los objetos centrales en la estructura narrativa del documental lo constituye un mapa, a través del que podemos navegar por los distintos personajes o por las secuencias del documental. De esta forma,

el uso del mapa como factor de localización, ubicación y consecución de un itinerario exploratorio es un elemento que insiste en el motivo principal del documental, la itinerancia, la búsqueda, el movimiento como parte de una estrategia que se enfrenta a la inmovilidad del pensamiento, el rastreo de respuestas 
a las preguntas que el propio espacio genera. (Arnau Roselló: 2014).

En relación a la interactividad, Arnau Roselló identifica en Prison Valley los tres tipos de interacción mencionados anteriormente. La interacción débil se plasma en la selección del idioma en la página de inicio

y en el acceso a determinados lugares de la aplicación que no ofrecen salida ni elementos navegables. La interacción media (interactivo-configurativa) está presenta en buena parte del film, y se manifiesta permanentemente en forma de opción interactiva al final de algunas secuencias (...) que permite o bien ampliar la experiencia con distintos objetos: foros, videos, fotografías, gráficos, etc., o bien continuar el camino, avanzando a la siguiente secuencia del documental. (Arnau Roselló: 2014).

La presencia de la interacción fuerte se manifiesta por ejemplo en secuencias como la diecinueve, de nombre "El miedo",

en la que tras las declaraciones de algunos personajes ya entrevistados en las secuencias anteriores, un par de cuadros de diálogo (...) abren un nuevo espacio de interacción. En él se nos muestra la pantalla partida horizontalmente y se nos ofrece la posibilidad de dar permiso al programa para que acceda a la conexión de nuestra propia webcam para grabar nuestro testimonio: En la parte superior, una línea navegable de videos individuales en los que el resto de personajes responden a la misma pregunta (¿Qué es para ti el miedo?), en la parte inferior otra línea de videos con las opiniones grabadas a través de la webcam de algunos internautas. (Arnau Roselló: 2014).

Finalmente, Arnau Roselló señala un aspecto muy particular de Prison Valley, que consiste en la existencia de una interfase cinemática, específicamente limitada al contenido relativo al cine de la ciudad (El Skyline Theatre), conformándose así como un rasgo metacinematográfico dentro del documental. 
Se trata de la interacción que permite el acceso a uno de los indicios que se sitúan encima de la cama en la habitación del motel, en la que podemos encontrar fotografías tipo Polaroid con un título a través de las que podemos acceder a un contenido adicional. Al penetrar en la correspondiente a 'Canyon City: Hollywood', se nos abre un nuevo espacio interactivo en el que podemos entrar en el cine, entrar en la sala para contemplar carteles de films rodados en la zona décadas atrás o subir a la sala de proyección, organizada en forma de fotografía panorámica navegable tal y como ocurre en el caso de la habitación del hotel. En este caso, el discurso metacinematográfico, que nos permite acercarnos al cine desde el propio cine y con sus herramientas (actualizadas), introduce una reflexión y un espacio de distanciamiento en el que el usuario se interroga sobre las mismas representaciones y su papel como parte del eje autoral de las mismas. (Arnau Roselló: 2014).

\section{A modo de cierre}

Como hemos visto, el campo del documental se encuentra en una instancia de gran apertura a nuevos formatos, técnicas, modalidades de navegación e interactividad, en suma, de enorme experimentación, si bien existen todo tipo de productos, desde aquellos que suponen un tipo de interactividad básica, a algunos otros que implican un desarrollo mucho mayor en este aspecto. La crítica de la realidad y su representación constituyen el centro de las problemáticas de una gran cantidad y calidad de documentales desde hace tiempo, ya sean lineales o interactivos, por lo que el desarrollo de los documentales interactivos supone una profundización y una actualización, posibilitada por las nuevas tecnologías de la información y la comunicación, de lo que ya viene teniendo lugar en el campo del documental subjetivo de autor. 


\section{Referencias bibliográficas}

ARNAU ROSELLÓ, Roberto (2014), "Mutaciones digitales del cine documental. Espacio narrativo e interacción en el webdocumental contemporáneo: Prison valley (Upian/Arte, 2010)". En Fotocinema. Revista Científica de Cine y Fotografía, número 9, pp. 7-34. Disponible en: http://repositori.uji.es/xmlui/handle/ $10234 / 126725$.

BERENGUER, Xavier (2004). A decade of interactive media. Temes de disseny, 21, pp. 30-35. Disponible en: http://www.calgran.net/ articles/decada /index.htm

BONINO, Filippo (2011), Is interactivity in interactive documentaries exploited at its full potential? MA on Interactive Media 2010/2011. London College of Communication. Disponible en: http://www.interactivedocumentary.net/wp-content/2011/09/final_ dissertation_Filippo-Bonino.pdf.

GIFREU CASTELLS, Arnau (2013): El documental interactivo como nuevo género audiovisual. Tesis doctoral UPF. Disponible en www.doc.ubi.pt/14/teses_arnau_castells.pdf.

MAURIN, Florent (2011): Course on i-docs design at the EMI-CFD. Disponible en: http://gamedesignconcepts.wordpress.com/2009/ 07/30/level-10-nonlinear-storytelling/.

MURRAY, Janet (1999): Hamlet en la holocubierta: el futuro de la narrativa en el ciberespacio, Paidós, Barcelona.

NICHOLS, Bill, La representación de la realidad: cuestiones y conceptos sobre el documental, Paidós, Barcelona, 1997. 
RYAN, Marie Laure (2001), Narrative as Virtual Reality: Immersion and Interactivity in Literature and Electronic Media, Johns Hopkins University Press, Baltimore. (2005): "Narrative and the Split Condition of Digital Textuality" en Videogame, Player, Text, Manchester University Press 2005.

\section{Sitios de interés}

Clase magistral a cargo de Josep $\mathrm{M}^{\mathrm{a}}$ Català: Flujos de lo visible: la expansión del documental: https://vimeo.com/33016851

Ma tribu c'est ma vie, documental interactivo: http://matribu.onf.ca/

The Challenge, documental interactivo: http://www.canalplus.fr/c-infosdocumentaires/pid3400-c-le-challenge.html

Becoming Human, documental interactivo:

http://www.becominghuman.org/

Tanatorama, documental interactivo:_http://www.thanatorama.com/

Bla bla bla 69, documental interactivo: http://blabla.onf.ca/

Darfur Game72, documental interactivo:

http://www.radiodabanga.org/darfurgame/english/game.html

The iron curtain diaries, documental interactivo:

http://www.theironcurtaindiaries.org/ 
El documental interactivo....

Black Friday, documental interactivo:

http://www.abc.net.au/blackfriday/home/default.htm

Comunidad de estudios del documental interactivo:

http://i-docs.org/

Prision Valley, documental interactivo: http://prisonvalley.arte.tv/?lang=en

Bear 71, documental interactivo

http://bear71.nfb.ca/\#/bear71

http://iambear71.tumblr.com/archive

Seat, las sombras del progesso, documental interativo www.sombrasdelprogresso.com

Solos, documental interactivo: www.webdocsolos .com/es

Proyecto Walsh, documental interactivo: http://proyectowalsh.com.ar

Sitio de la TVE http://lab.rtve.es/webdoc

Sitio de juegos digitales para el cambio social http://www.gamesforchange.org/ 